\title{
LA CIUDADANÍA CUBANA. MIRANDO ALREDEDOR Y AL PASADO PARA RESOLVER UN PROBLEMA DE HOY ${ }^{1}$
}

THE CUBAN CITIZENSHIP. LOOKING AROUND AND TO THE PAST TO RESOLVE THE ACTUAL PROBLEM

Martha PRIETO VALDÉs

RESUMEN: El tratamiento de la ciudadanía ha sido algo contradictorio a través de la historia; de institución de derecho civil que diferenciaba a los hombres y le permitía la implicación en el espacio público, ha llegado a ampliar las fronteras en el propio "envase" de lo público, con incidencia directa en lo civil y lo social. Es fórmula que sirve no solamente para la inclusión de unos, sino de participación plena de todos en la toma de decisiones y en la protección de la vida. Mirando a Cuba, el estudio se realiza desde lo histórico hacia el presente, para identificar principios rectores en las regulaciones constitucionales, con la finalidad de dar luces para la solución de problemáticas presentes en torno a la dos y la doble ciudadanía.

Palabras claves: ciudadanía, nacionalidad, doble y dos ciudadanías

ABSTRACT. The treatment of the citizenship has been something contradictory through the history; of civil right institution that differentiated the men, and allowed the implication in the public space, it has ended up enlarging the frontiers in the own "container" of the public thing, with direct incidence in the civil and social spheres. It is the formula not only good for the inclusion of some, but of full participation of all in taking of decisions and in the protection of the life. Looking at Cuba, the study is carried out from the historical thing toward the present in order to identify principles in the constitutional regulations, with the purpose of giving lights for the solution of present problems about two and double citizenship.

Keywords. Citizenship, Nationality, Double and two Citizenships

SUMARIO: I. Institución público-privada. II. La ampliación a lo social. III. Confusión terminológica y sus efectos. IV. Pérdida y múltiple ciudadanía. Un problema a resolver. V. Conclusiones. VI. Bibliografía.

\section{INSTITUCIÓN PÚBLICO-PRIVADA}

La noción de un fenómeno o institución incide directamente en su instrumentación posterior, y la problemática aumenta si además han existido diversos criterios al

\footnotetext{
${ }^{1}$ Artículo recibido el 26 de noviembre de 2014 y aceptado para su publicación el 30 de junio de 2015.

${ }^{2}$ Doctora en ciencias jurídicas; profesora titular (catedrática) de derecho constitucional y teoría general del derecho, Facultad de Derecho, Universidad de La Habana.
} 
respecto; esta es la situación en cuanto a la ciudadanía. Afirmar que la ciudadanía ha tenido un tratamiento contradictorio a través de la historia no es nuevo; ello también se ha reflejado en posiciones asumidas por grandes políticos o jurisconsultos, y en las determinaciones adoptadas. Aristóteles, en su obra Política ya se planteaba que “...a quién puede darse el nombre de ciudadano y qué es lo que quiere decir (es una) cuestión controvertida muchas veces y sobre la que las opiniones no son unánimes, teniéndose por ciudadano en la democracia uno que muchas veces no lo es en un Estado oligárquico"; ${ }^{3}$ de lo cual deriva ya desde aquel entonces un reclamo de clara determinación del contenido del mismo. Tales diferencias se conservaron, al menos si seguimos a Rousseau, quien para 1762 afirmaba:

Solamente los franceses toman familiarmente este nombre, porque no tienen verdadera idea de lo que la palabra ciudadano significa, como puede verse en sus diccionarios, sin que incurran, usurpándolo, en crimen de lesa majestad: este nombre entre ellos expresa una virtud y no un derecho. Cuando Bodin ha querido hablar de nuestros ciudadanos y habitantes, ha cometido un grave yerro tomando los unos por los otros...".

Y siguió diciendo: “Ningún autor francés, que yo sepa, ha comprendido el verdadero sentido del vocablo ciudadano". ${ }^{4}$

Ello en cierto modo pudo haber sido resultado de la influencia del criterio de los griegos sobre la ciudadanía ${ }^{5}$ de las decisiones de los emperadores romanos sobre los habitantes del imperio, como el otorgamiento de la ciudadanía como reconocimiento a la virtud. ${ }^{6}$

3 Aristóteles, Política, libro III, cap. I, “Del Estado y del ciudadano", en http://bib.cervantesvirtual.com/servlet/SirveObras/13561630989134941976613/index.htm.

${ }^{4}$ Rousseau, J. J., “El contrato social”, Obras escogidas, La Habana, Ciencias Políticas, Edit. Ciencias Sociales, 1973, libro I, p. 613.

5 “...El ciudadano debía obedecer antes de mandar; de todo lo cual concluimos que al legislador toca educar a los ciudadanos en la virtud, conociendo los medios que conducen a ella y el fin esencial de la vida más digna". Aristóteles, Política, libro IV, cap. XIII, cit.

${ }^{6}$ Pompeyo, hijo de Sexto, imperator, según decisión del Consejo (de oficiales en campaña) y en virtud de la ley Julia, proclamó ciudadanos romanos a los jinetes hispanos a causa de su valor. Véase “Decretum cn. Pompei strabonis de civitate equitibus hispanis danda (Bronce de Ascoli), (89 a. C.)", en Fatás, G., Historia de Zaragoza, I, Zaragoza, 1997, p. 55, en http://webu2.upmfgrenoble.fr/DroitRomain/Spanica/pompei_esp.htm/. 
De tal suerte, la noción de ciudadanía como virtud también llevó a su confusión como las demás categorías con las que se relaciona, y de una manera u otra ha llegado hasta hoy, motivo por lo cual siempre merece revisar, aunque sea someramente, el tracto histórico de esta institución.

De ser concebida como condición que prestigiaba al hombre y le permitía a los libres ser titulares de bienes y disponer de manera independiente de su estatus personal, era también instrumento de discriminación, por las restricciones que suponía no ostentarla. Al permitirle participar en sociedad, dio paso al ente político que elaboraba sus leyes ${ }^{7}$ y contribuía hasta con la vida a su protección, como fue la extensión de la ciudadanía a los habitantes del imperio romano, en tiempos de Caracalla, ${ }^{8}$ aunque también tuvo fines económicos y militares. He aquí otra diferenciación de la noción original.

En el periodo de formación del Estado nación y el ascenso de la burguesía al poder, la ciudadanía significó la ruptura de los hombres con los vínculos que les unían a los señores, a la tierra, a la Iglesia... ${ }^{9}$

El ciudadano comenzó a ser la fuerza económica del cambio y constituyó el "pasaporte" que autorizaba la participación en la vida política; volvió a ser instrumento de inclusión y exclusión al potenciar el disfrute de derechos civiles y políticos, cuando es sabido que su determinación estuvo vinculada a la esfera económica. Así, en los primeros documentos de esta segunda época, el ciudadano fue

\footnotetext{
${ }^{7}$ Sobre este carácter político, véase Aristóteles, op. cit., libro III, cap. IX: “Hay, por tanto, indudablemente diversas especies de ciudadanos, y sólo lo es plenamente el que tiene participación en los poderes públicos ...Toda la discusión precedente ha demostrado en qué la virtud del hombre de bien y la virtud del ciudadano son idénticas, y en qué difieren; hemos hecho ver, que en un Estado el ciudadano y el hombre virtuoso no son más que uno, que en otro se separan; y en fin, que no todos son ciudadanos, sino que este título pertenece sólo al hombre político, que es o puede ser dueño de ocuparse, personal o colectivamente, de los intereses comunes".

8 “(L'Empereur César) Marc Aurèle Sévère Antonin Auguste proclame: ...Je donne donc à tous (les pérégrins qui sont dans) l'Empire le droit de cité romaine, étant entendu [que sont maintenues les cités de toute sorte] excepté celles des déditices. Il se doit en effet que (la multitude... non seulement...) ...tout, mais qu'elle soit dès maintenant associée aussi à la victoire. Et le présent édit augmentera (?) la majesté du (peuple) romain ...Édit de Caracalla conférant aux habitants de l'empire le droit de cité romaine (211212 apr. J.-C.)". Gaudemet, J., Les institutions de l'antiquité, 7a. ed., París, 2002, pp. 315-316. http://webu2.upmf-grenoble.fr/DroitRomain/Francogallica/Caracalla_fran.htm.

${ }^{9}$ Linde, E., “La ciudadanía europea: un peldaño en la construcción del hombre de nuestro tiempo”, p. 89, en $h t t p: / / d i a / n e t . u n i r i o j a . e s$.
} 
Esta revista forma parte del acervo de la Biblioteca Jurídica Virtual del Instituto de Investigaciones Jurídicas de la UNAM

considerado como nuevo ente para defender la res publicae, ${ }^{10}$ pero limitado por la cuantía de sus recursos financieros e ilustración.

Ya para los albores del siglo XIX la ciudadanía era expresión de la titularidad de derechos civiles y potenciadora de los políticos. ${ }^{11}$ En el plano de la normativa jurídica también se manifestó esta dualidad de lo privado y lo público, en tanto su adquisición y efectos eran regulados en los códigos civiles, como fue el caso del Código Civil español de $1889,{ }^{12}$ en las primeras Declaraciones de la época moderna y las Constituciones codificadas era precondición necesaria para participar en la vida política. $^{13}$

Y si en Europa la invocación al ciudadano supuso el rescate del hombre capaz de incorporarse a la toma de decisiones políticas y poder disfrutar del derecho al voto, igual que los derechos civiles, en plano de igualdad; en América Latina, su determinación diferenciada de la metropolitana fue una vía para asegurar la independencia nacional y del hombre libre del antiguo yugo esclavista y colonial.

En nuestra América también se empleó la ciudadanía en ese doble carácter inclusivo-excluyente. Ser ciudadano era el reconocimiento del estado de libertad civil

\footnotetext{
${ }^{10}$ A participar en la elaboración de las leyes, directamente o por medio de representante, a la igualdad ante la ley, a las libertades de palabra e imprenta, a verificar el empleo de su contribución pública. Declaración de los Derechos del Hombre y del Ciudadano de 1789, artículos 6o., 11 y 14.

${ }^{11}$ Según Th. Marshall, en el siglo XIX la ciudadanía en forma de derechos civiles era universal, pero el sufragio político no era uno de los derechos de ciudadanía; sino que era el privilegio de una clase económica escogida. Marshall, Th., "Ciudadanía y clases sociales", JSTOR: Reis, Revista Española de Investigaciones Sociológicas, núm. 79, julio-septiembre, 1997, p. 308.

12 Código Civil español de 1889, artículo 17: “Son españoles: 10. Las personas nacidas en territorio español.; 2o. Los hijos de padre o madre españoles, aunque hayan nacido fuera de España; 3o. Los extranjeros que hayan obtenido carta de naturaleza; 40. Los que, sin ella, hayan ganado vecindad en cualquier pueblo de la Monarquía", en https://Www.boe.es/buscar/act.php?id=BOE-A-1889$4763 \& \operatorname{tn}=1 \& v d=\& p=18890725$.

${ }^{13}$ Constitución de Francia de 1791, título II, artículo 10., inciso 9o.: “Los ciudadanos que componen cada comuna tienen el derecho de elegir entre ellos, según la forma determinada por la Ley, los que, con el título de Oficiales municipales, estarán encargados de administrar los asuntos particulares de la comuna. Podrán delegarse a los oficiales municipales algunas funciones relativas al interés general del Estado"; Constitución de Francia de 1793, artículos 50.: “Todos los ciudadanos tienen el mismo derecho a los empleos públicos. Los pueblos libres no conocen más motivos de preferencia, en sus elecciones, que las virtudes y el talento"; y 29: "Cada ciudadano tiene el mismo derecho para concurrir a la formación de la ley y al nombramiento de sus mandatarios o agentes".
} 
y política alcanzada, ${ }^{14}$ del nacido en este lado del océano ${ }^{15} \mathrm{o}$ en cualquier otro siempre y cuando hubiera luchado por la independencia del pueblo. ${ }^{16} \mathrm{~A}$ la vez, se evitaba que el colonizador o representante de la vieja metrópoli participara en la vida política de las nuevas Repúblicas, algunas de las que, una vez constituidas, también limitaron a los propios por su falta de saber, ${ }^{17}$ arrastrándose tal restricción hasta mediados del pasado siglo ${ }^{18}$ cuando ya se defendía la soberanía popular.

Siguiendo la línea anterior, e igual que en las primeras Constituciones latinoamericanas, vale decir que en Cuba durante el constitucionalismo mambí, o pre-estatal, la ciudadanía fue objeto de regulación desde la consideración del hombre libre, que tenía derechos y deberes para con la patria.

Con el carácter antes señalado se advierte en la Constitución de Guáimaro, la primera de nuestros textos. Aquí el vocablo "ciudadano" se empleó para denominar a los hombres nacidos en el territorio ultramarino, pero vinculados al fenómeno político, a una República en formación y con deberes para con ella y más ninguna otra. ${ }^{19}$ Era la manera de defender una nueva identidad frente a la metropolitana.

${ }^{14}$ Constitución de las Provincias Unidas del Centro de América de 1824, artículo 13: “Todo hombre es libre en la República. No puede ser esclavo el que se acoja a sus leyes, ni ciudadano el que trafique en esclavos". Constitución de Bolivia de 1826, artículo 11 inciso 5o.: “Todos los que hasta el día han sido esclavos: y por lo mismo quedarán de derecho libres, en el acto de publicarse la Constitución...".

${ }^{15}$ Constitución de Apatzingán de 1814, México, artículo 13: “Se reputan ciudadanos de esta América todos los nacidos en ella".

${ }^{16}$ Constitución de Argentina de 1826, artículo 40.: “Son ciudadanos de la Nación Argentina: primero, todos los hombres libres, nacidos en su territorio, y los hijos de éstos, donde quieran que nazcan; segundo, los extranjeros que hayan combatido o combatieren en los ejércitos de mar y tierra de la República"; Constitución de Bolivia de 1826, artículo 11: "Son bolivianos: 10. Todos los nacidos en el territorio de la República... 3o. Los que en Junín o Ayacucho combatieron por la libertad..."; Constitución del Uruguay de 1830, artículo 11: “La ciudadanía se suspende: ...50. Por no saber leer ni escribir, los que entren al ejercicio de la ciudadanía desde el año de mil ochocientos cuarenta en adelante".

${ }^{17}$ Constitución de Chile de 1822, artículo 14: “Son ciudadanos todos los que tienen las calidades contenidas en el Artículo 40. con tal que sean mayores de veinticinco años o casados y que sepan leer y escribir...".

${ }^{18}$ Constitución de la República del Perú de 1933, artículo 86: “Gozan del derecho de sufragio los ciudadanos que sepan leer y escribir"; Constitución de Nicaragua de 1948, artículo 28: "Son ciudadanos los nicaragüenses mayores de veintiún años y los mayores de dieciocho que sepan leer y escribir...".

${ }^{19}$ Constitución de Guáimaro de 1869, artículos 40.: “Sólo pueden ser Representantes los ciudadanos de la República de veinte años"; 80.: "Ante la Cámara de Representantes deben ser acusados, cuando 
Ya en el último texto de este periodo, el de La Yaya de 1897, cuya vigencia se vio interrumpida por la intervención estadounidense, el vocablo "cubano" fue el más utilizado; el que determinaba la condición jurídica política del hombre, potenciaba derechos y deberes para con la patria. ${ }^{20}$ El término "ciudadanía" sólo se empleó en la denominación del título y el requisito para ser presidente de la República en armas; ${ }^{21}$ no se previó como precondición para otros derechos: se luchaba por la libertad de todos los de adentro del territorio, y cubano-ciudadano debía ser su presidente.

\section{LA AMPLIACIÓN A LO SOCIAL}

Ya para la primera mitad del pasado siglo, en el resto del mundo, los reclamos sociales hicieron que se volviera la mirada a la ciudadanía, ya no restringida a lo individual, civil y político, sino para potenciar inclusión en el disfrute de derechos de las amplias colectividades poblacionales, ampliándose ella como manto protector hasta los derechos culturales, laborales, de prestación social. Ser ciudadano posibilitaba intervenir en las múltiples decisiones cotidianas y ejercer soberanía; pero si debía aportar a lo común, debía dejar de ser instrumento de beneficio para el gran capital y pasar a ser sujeto de derechos y disfrutar lo construido.

En nuestra América, las Constituciones del primer cuarto de siglo aún conservaron el carácter eminentemente político de la ciudadanía, vinculado a lo electoral; de hecho, sólo participaban los nacionales considerados ciudadanos. Ejemplos varios, pero baste mencionar los textos de Chile de 1925, y del Ecuador de $1929 .^{22}$

hubiere lugar, el Presidente de la República, el General en Jefe y los miembros de la Cámara. Esta acusación puede hacerse por cualquier ciudadano: si la Cámara la encuentra atendible, someterá el acusado al Poder Judicial”; 25: “Todos los ciudadanos de la República se consideran soldados del Ejército Libertador"; y 27: “Los ciudadanos de la República no podrán admitir honores ni distinciones de un país extranjero".

${ }^{20}$ Constitución de La Yaya de 1897, artículos 20.: “Son cubanos: ...30. Las personas que estén al servicio directo de la Revolución, cualquiera que sea su nacionalidad de origen".

${ }^{21}$ Ibidem, artículo 19: “Para ser Presidente o Vicepresidente se requiere ser cubano de nacimiento o ciudadano cubano con más de diez años de servicios a la causa de la Independencia de Cuba; haber cumplido la edad de treinta años...".

${ }^{22}$ Constitución de Chile de 1925, artículo 7o.: “Son ciudadanos con derecho a sufragio los chilenos que hayan cumplido veintiún años de edad, que sepan leer y escribir, y estén inscritos en los registros electorales"; y Constitución del Ecuador de 1929, artículo 18: “Para ser elector se requiere ser ciudadano en ejercicio y no estar comprendido en las incapacidades establecidas por la ley". 
Cuba, ya como Estado formalmente constituido, en su primer texto de 1901 no reguló la adquisición o pérdida de la ciudadanía, sino de la "condición de cubano", ${ }^{23}$ que determinaba el disfrute de los demás derechos y la exigencia de ciertos deberes, con una noción ius privatista. No obstante, sí empleó el término para establecer el pre-requisito necesario para asumir cargo público. ${ }^{24}$

Luego en 1936, y más tarde en 1940, el vocablo "ciudadanía" se empleó con carácter más genérico: de público. ${ }^{25}$ Pero vale señalar que hay una marcada diferencia con lo preceptuado en 1869, pues aquí ya existía el Estado con reconocimiento internacional, y ostentarla suponía determinados límites también. Así, en sentido general los derechos y deberes se reconocían para los cubanos, nacidos o naturalizados.

Las leyes constitucionales que de manera inmediata le precedieron al texto de 1940 muestran ese reclamo de lo social; por ejemplo, la Ley constitucional de 1934 consagró las obligaciones que derivaban de la condición de cubano, ${ }^{26}$ lo que muestra un cambio de posición frente al viejo individualismo.

\footnotetext{
${ }^{23}$ Constitución Cuba de 1901, artículos 40. y 80.; 40.: “La condición de cubano se adquiere por nacimiento o por naturalización. 70. La condición de cubano se pierde: 10. Por adquirir ciudadanía extranjera; 20. Por admitir empleo u honores de otro Gobierno sin licencia del Senado; 3o. Por entrar al servicio de las armas de nación extranjera sin la misma licencia; 4o. Por residir el cubano naturalizado cinco años continuos en el país de su nacimiento, a no ser por razón de empleo o comisión del Gobierno de la República"; 80.: "La condición de cubano podrá recobrarse con arreglo a lo que prescriben las leyes". Nótese la Ley Constitucional del 3 febrero 1934, cuyos artículos 40., 60. y 80. tienen idéntica regulación que el texto de 1901, pero difiere en cuanto a los deberes, artículo 9o., adicionando el deber de prestar... cuantos servicios sean necesarios en los casos de emergencia, según se determine en Decretos-Leyes.

${ }^{24}$ Constitución de Cuba de 1901, artículos 40.: "La condición de cubano se adquiere por nacimiento o por naturalización”, y 76: "Para el ejercicio de sus atribuciones tendrá el Presidente de la República, los Secretarios del Despacho que determine la ley; debiendo recaer el nombramiento de éstos en ciudadanos cubanos que se hallen en el pleno goce de los derechos civiles y políticos".

${ }^{25}$ Constitución de Cuba de 1940, artículo 39: “Solamente los ciudadanos cubanos podrán desempeñar funciones públicas que tengan aparejada jurisdicción".

${ }^{26}$ Ley Constitucional de Cuba de 1934, artículo 90.: “Todo cubano está obligado: Primero. A servir a la Patria con las armas y en la forma que prescriben las leyes; Segundo. A prestar cuantos servicios sean necesarios en los casos de emergencia, según se determine en Decretos-Leyes; Tercero. A contribuir a los gastos públicos en la forma y la proporción que dispongan las leyes". Es de destacar también, el artículo 32 de la precitada Ley, en el que se incorpora al grupo de derechos fundamentales de carácter individual el derecho a la enseñanza, consignándose además la de nivel primario como obligatoria.
} 
Al amparo del texto de 1940 se reconocieron múltiples derechos sociales, además de los civiles y políticos, de disfrute individual y colectivo, ${ }^{27}$ lo que evidencia ese cambio de noción respecto a las facultades del sujeto titular de los derechos, pues no me atrevo a restringirlo a los ciudadanos, por no ser la expresión que más se emplea en el texto, sino la condición de cubano. En apoyo a lo antes señalado, vale tener presente el artículo 10, que enuncia claramente cuáles se reconocen al ciudadano. ${ }^{28}$ Sólo que el hecho de que los preceptos más democráticos de este texto no fueron instrumentados hizo que quedaran en el limbo, a la espera de las leyes de desarrollo, y la ampliación de derechos, la noción ya no sólo política y civil, sino social e incluyente, se quedó en la linda letra constitucional. De todas formas, en cuanto a la forma de regulación y principios contenidos en los textos en esta esfera, sí valdría desde el presente mirar al pasado, no sólo por cultura jurídica, o para encontrar raíces, sino porque algunas disposiciones dictadas al amparo de este texto de 1940 han pervivido, como es el Decreto 358 de 1944, regulador de la adquisición de la ciudadanía que mantiene vigencia parcial.

Esa misma línea de acciones y reclamos populares por la ampliación de los derechos, y con carácter igual para todos, se dio paso a una noción de una ciudadanía incluyente, que ya para esta altura suponía ser la institución que, al menos formalmente, posibilitaba el disfrute de los derechos civiles, políticos y sociales, ${ }^{29}$ como bien expuso Th. Marshall años más tarde.

Otro criterio, mucho más general, pudiera significarse respecto a la ciudadanía en calidad de estatus amplio y de reconocimiento, también, de lo social con un sentido más abarcador, en tanto institución resultante de la conjugación de los elementos del

\footnotetext{
${ }^{27}$ Constitución de Cuba de 1940, como ejemplo, algunos de los preceptos de este tipo, artículos 65: “...el seguro social como derecho irrenunciable de los trabajadores, con el concurso equitativo de patronos, trabajadores y Estado”; 66: “...jornada laboral máxima de 8 horas”; 79: “...fomento estatal de viviendas baratas para obreros"; 80: “...asistencia social a cargo del Estado”, 90: “...proscripción del latifundio y limitación restrictiva para los extranjeros para adquirir y poseer tierras, así como medidas para su reversión a favor de cubanos".

${ }^{28}$ Constitución de Cuba de 1940, artículo 10: “El ciudadano tiene derecho: a) A residir en su patria sin que sea objeto de discriminación ni extorsión alguna, no importa cuáles sean su raza, clase, opiniones políticas o creencias religiosas; b) A votar según disponga la ley en las elecciones y referendos que se convoquen en la República; c) A recibir los beneficios de la asistencia social y de la cooperación pública, acreditando previamente en el primer caso su condición de pobre; d) A desempeñar funciones y cargos públicos; e) A la preferencia que en el trabajo dispongan la Constitución y la ley".

${ }^{29}$ Marshall, Th., op. cit., p. 323.
} 
Estado, de la existencia de una población que nace o se desarrolla en el territorio bajo jurisdicción estatal y en un espacio de natural y de cultura común. Ello supone que de ese vínculo - tanto el Estado, los entes colectivos o el hombre- se generan y asumen derechos, deberes y responsabilidades, propias y para con el otro y los otros. Esta es una noción de ciudadanía incluyente, que suma actores y en todas las esferas sociales, ${ }^{30}$ de una población cada vez más plural y multicultural. ${ }^{31}$ Pero más recientemente, la conformación de nuevos espacios políticos comunes ha hecho resurgir, a escala internacional, la importancia del término, ${ }^{32}$ que antes era patrimonio de las Constituciones nacionales, como expresión de los reclamos de participación directa a todos los niveles y ámbitos de la vida social, que no quiere verse excluida en la determinación de sus destinos y en el goce de lo que le pertenece pues lo ha construido.

En Cuba, esa mezcla de lo público y lo privado ha pervivido de manera similar al texto de 1940, en la ley fundamental de 1959 y posteriormente en la Constitución de 1976; incluso valdría adicionar que hasta 1976 en que entró en vigor el actual texto se reguló la obtención de la ciudadanía tanto en la ley fundamental de 1959 como en el Código Civil de 1888 por ese entonces vigente con modificaciones. ${ }^{33}$ De tal suerte, pudiéramos mirar al pasado para encontrar soluciones a fenómenos actuales, si es que aún perviven algunos de aquellos espíritus.

Un giro en la noción se apreció en el texto de 1976, que ponderó los derechos sociales, los hizo realidad con garantías materiales aportadas por el Estado y los antepuso en su regulación por sobre los civiles y políticos; se adoptaron medidas para asegurar los primeros en plano de igualdad para ciudadanos y residentes

\footnotetext{
${ }^{30}$ Borja, J., "La ciudad y la nueva ciudadanía”, conferencia en Fórum Europa, Barcelona, junio de 2001; http://www.diba.cat/forumeuropa/documents.2001/Borja.doc.

${ }^{31}$ Kymlicka, W. y Norman, W., “El retorno del ciudadano. Una revisión de la producción reciente en teoría de la ciudadanía", AsorA, núm. 7/1997, pp. 5-42; http://courseware.url.edu.gt.

32 Tratado constitucional de la Unión Europea, 2004; título II, artículos I.9.3: "Los derechos fundamentales que garantiza el Convenio Europeo para la Protección de los Derechos Humanos y de las Libertades Fundamentales y los que son fruto de las tradiciones constitucionales comunes a los Estados miembros forman parte del derecho de la Unión como principios generales”; y I.10.1: “Toda persona que tenga la nacionalidad de un Estado miembro posee la ciudadanía de la Unión, que se añade a la ciudadanía nacional sin sustituirla". EUR-Lex, Diario Oficial, C 310; 47 año, 16 diciembre 2004, en http://eur-lex.europa.eu/JOHtmI.do?uri=OJ:C:2004:310:SOM:ES:HTML.
}

${ }^{33}$ Ley Fundamental de la República de Cuba de 1959, artículos 80. al 18; y Código Civil de 1888, modificado, artículos 17-26. 
permanentes. Los civiles y políticos se regularon, no todos, en artículos siguientes, enunciando garantías jurídicas, remisiones legales, definiendo los límites de su ejercicio en la sociedad, los que aún requieren de completamiento, tanto al reconocimiento ordinario como en su carácter de extraordinarios o humanos esenciales, a fin de que la ciudadanía, como institución, conserve su integralidad y esencia.

De todo lo antes expuesto es fácil apreciar que los reclamos de ampliación o inclusión ciudadana, concebida esta institución como el estatus o condición legal que indica la pertenencia a una comunidad política, resultado de la cual se tiene acceso por igual a un conjunto de derechos y deberes que tal relación implica, parten de una visión bastante ideal del fenómeno cuando se obvia la condición económica, civil y política del hombre genérico en sí mismo y de la sociedad en que se inserta. La diferencia entre igualdad material y jurídica, entre realidad y posibilidad, tanto en los análisis comparativos como en las exigencias de aseguramiento y realización nacional, pautan su ejercicio pleno. El breve tracto histórico muestra que las prácticas sociales, las coyunturas políticas y económicas, así como el funcionamiento del sistema político y jurídico, ${ }^{34}$ condicionan la dinámica del ser ciudadano.

¿Qué tipo de institución es? En todo caso, la ciudadanía ha sido precondición para el reconocimiento o ejercicio de derechos y cumplimiento de deberes, primeramente civil, luego político y más tarde social. Aquí, también, en esta pluralidad de derechos está una de las bases de su reclamo permanente ante las confusiones o restricciones que a través de la historia se han advertido.

\section{CONFUSIÓN TERMINOLÓGICA Y SUS EFECTOS}

La respuesta a la pregunta anterior también requiere de la aclaración de una confusión presente: dos vocablos con esencia diferente, que designan contenidos distintos, o también empleados indistintamente para definir lo mismo: el par nacionalidad-ciudadanía.

El Diccionario de la lengua española define a la nacionalidad como aquella condición y carácter peculiar de los pueblos y habitantes de una nación; y la

\footnotetext{
${ }^{34}$ Para abundar al respecto, Andrenacci, L., “Imparis civitatis. Elementos para una teoría de la ciudadanía desde una perspectiva histórica", Memoria Académica, FaHCE, Cuadernos del CISH; 2003; núms. 13 y 14, pp. 86 y ss., http://Www.memoria.fahce.un/p.edu.ar/art_revistas/pr.379/pr.379.pdf.
} 
ciudadanía, como cualidad y derecho de ciudadano, ${ }^{35}$ siendo este último el que pauta la comprensión del fenómeno actual. Si partiéramos de la lógica lexicológica nacionalidad-nación-nacimiento y ciudadanía-ciudad-Estado-implicación políticosocial, no habría hoy muchas confusiones en cuanto a denominación, pero habría que determinar a quién reconocerle o asignarle derechos, marcando la relación inclusión-exclusión.

De primar la condición de nacional, el elemento sociológico sería el que paute y condicione el jurídico, pero no podrán ser limitados los derechos de los naturales, independientemente del lugar donde se encuentren, pues es ésta la precondición para la plenitud del ejercicio de los derechos que derivan de tal estatus. Sólo que esta fórmula sería excluyente respecto a los residentes no nacionales que también aportan al desarrollo social. En la actualidad se trata de uno de los temas más ampliamente debatidos, en especial ante las grandes migraciones que se producen en busca de mejorías económicas, huyendo de crisis y desastres, no sólo militares sino también ambientales. Es entonces cuando la preferente previsión de derechos para los naturales como noción garantista de inclusión genera exclusión.

No obstante los efectos antes señalados, múltiples Constituciones reconocen a la nacionalidad como la condición básica para el establecimiento de derechos y deberes en la sociedad, ${ }^{36}$ y las leyes civiles y reguladoras de los intercambios comerciales asumen este vocablo para identificar la ley aplicable ante conflictos de leyes, en especial ante la presencia del elemento extranjero. $Y$ es, además, concebida como aquella condición que permite reclamar la protección del Estado respecto a los más disímiles derechos, aun encontrándose en el exterior. ${ }^{37}$ Asimismo, es reconocido

\footnotetext{
35 Nacionalidad: “1o. f. Condición y carácter peculiar de los pueblos y habitantes de una nación; 20. f. Estado propio de la persona nacida o naturalizada en una nación; 3o. f. Esp. Comunidad autónoma a la que, en su Estatuto, se le reconoce una especial identidad histórica y cultural; 4o. f. Esp. Denominación oficial de algunas comunidades autónomas españolas". Ciudadanía: “1o. f. Cualidad y derecho de ciudadano; 2o. f. Conjunto de los ciudadanos de un pueblo o nación; 3o. f. Comportamiento propio de un buen ciudadano". Real Academia Española, Diccionario de la lengua española, 22a. ed., 2010.

${ }^{36}$ Constitución de Chile de 1980, artículo final: “Un decreto ley determinará la oportunidad en la cual se efectuará el señalado plebiscito, así como las normas a que él se sujetará, debiendo establecer las reglas que aseguren el sufragio personal, igualitario y secreto y, para los nacionales, obligatorio". Igual emplea nacionalidad la Constitución de Costa Rica de 1949; de Colombia de 1991 y de República Dominicana de 2010.

${ }^{37}$ Preceptos permanentes en los códigos civiles, tanto antiguos como modernos; por ello se aporta sólo un ejemplo: Código Civil de Honduras de 1934, artículo 13: “Las leyes relativas a los derechos y deberes
} 
como precondición para la titularidad de derechos patrimoniales, en especial si los bienes son recursos naturales valiosos para la colectividad. ${ }^{38}$

De admitir a la ciudadanía como institución que marca el vínculo con el Estado, ofrece la posibilidad de inclusión de los no nacionales que se naturalicen -esto es una muestra de la fusión y confusión-; pero mejor sería que se ciudadanicen, o que se acojan a la ciudadanía del Estado, ${ }^{39}$ a fin de posibilitar el disfrute de todos los derechos por igual.

Una somera revisión de los textos latinoamericanos permite advertir el uso de ambos términos, y cada uno de ellos es precondición para el disfrute de derechos. Valga sólo citar las Constituciones de Guatemala de 1985, ref. 1993, o de Colombia de 1991, y más recientemente el de República Dominicana, de 2010. En éstos, la nacionalidad se adquiere básicamente con el nacimiento, hecho a partir del cual se tiene la posibilidad de acceder a derechos civiles y sociales en tanto humanos fundamentales; mientras que es la ciudadanía la que posibilita el acceso a los derechos políticos a partir de la mayoría de edad.

Esta doble utilización de categorías condicionadoras de derechos diferentes, por un lado asegura unos, y por otro excluye a los no nacionales residentes de la plena participación en la toma de decisiones políticas, algo que también es de interés para ellos.

El empleo de la nacionalidad, o de la ciudadanía, como categorías básicas, ciertamente es un problema de determinación propia de cada Estado-pueblo en sus textos constitucionales; pero la dificultad se presenta cuando se produce el intercambio humano en los procesos migratorios, cuando se hace necesario fijar el círculo de derechos que le corresponde a la persona y la ley aplicable en caso de conflicto, aunque el contenido al cual se refieren sea el mismo; la esencia de los términos lleva a otra consideración.

\footnotetext{
de familia o al estado, condición y capacidad legal de las personas, obligan a los hondureños, aunque residan en país extranjero".

${ }^{38}$ Constitución de México de 1917, artículo 10.: “Sólo los mexicanos por nacimiento o por naturalización y las sociedades mexicanas tienen derecho para adquirir el dominio de las tierras, aguas y sus accesiones, o para obtener concesiones de explotación de minas o aguas".

${ }^{39}$ Constitución de Argentina de 1994, artículo 21: “Todo ciudadano argentino está obligado a armarse en defensa de la patria y de esta Constitución, conforme a las leyes que al efecto dicte el Congreso y a los decretos del Ejecutivo nacional. Los ciudadanos por naturalización son libres de prestar o no este servicio por el término de diez años contados desde el día en que obtengan su carta de ciudadanía".
} 
Los inconvenientes aumentan cuando un pueblo desarrolla su proceso de elaboración constitucional y bebe de otras doctrinas y normas foráneas sin tener en cuenta las nociones imperantes en uno $u$ otros; entonces se pueden crear confusiones que resultan de las mezclas.

Teniendo en cuenta lo anterior, es necesario realizar una toma de partido respecto a las varias categorías implicadas -y que en su regulación jurídica se interconectan con la ciudadanía-, pues las confusiones en la noción de cada una o en su regulación, no sólo limitan un claro entendimiento de qué es, sino incluso en la determinación de los posibles efectos jurídicos que derivan de ellas.

¿Cuál de ellas, nacionalidad o ciudadanía, ha de tener la responsabilidad en la determinación de los derechos? La doctrina no puede obligar, pero sí sugerir. Si partimos de concebir al ente natural como nacional, formado en el seno de un grupo humano del cual se deriva su identidad, sus valores y la existencia de una cultura común; de la condición de nacional resultan entonces idiosincrasia, cultura, identidad. Ser nacional —o la nacionalidad - se presenta como una categoría sociosicológica y cultural, pero no implica más derechos como no sean los relativos a su reconocimiento, respeto y protección en aquellas esferas. La asunción de la nacionalidad como institución que identifica pertenencia al grupo hoy está muy a tono con nociones pluralistas esgrimidas desde la propia América Latina -aunque no es excluyente respecto a otros espacios geográficos-, y que posibilitan el reconocimiento de la identidad de diversos grupos humanos originarios y su derecho a un derecho propio. Entonces, dejaríamos ciudadanía para fijar el vínculo con el Estado y generadora de derechos y deberes para ambas partes de la relación.

La distinción anterior podría resolver la confusión que pervive entre nosotros. Puede apreciarse que las diferentes Constituciones adoptadas desde 1869 no han sido armónicas en el empleo de los términos objeto de análisis, y mientras las mambisas y la de 1901 regularon la condición de cubano, como presupuesto de diferenciación del español; esta última ya empleaba el término de "ciudadanía" para referirse al natural cubano que adquiriera otra extranjera. ${ }^{40}$

A principios del siglo pasado, en el plano doctrinal la nacionalidad era precondición para el disfrute de la ciudadanía, potenciando ambas derechos diferentes. Muestra de tales nociones puede apreciarse en el Código de Bustamante,

\footnotetext{
${ }^{40}$ Constitución de Cuba de 1901, artículo 70.: “La condición de cubano se pierde: 10. Por adquirir ciudadanía extranjera...".
} 
cuando en su artículo 3o. señala a la nacionalidad como patrón para la determinación de los derechos civiles y para el goce de las garantías individuales. ${ }^{41}$

Más tarde, en 1936, y posteriormente en 1940, adquirió carácter más genérico, público. Fue la propia Ley constitucional de 1936 la que introdujo la señalada confusión entre nacionalidad y ciudadanía entre nosotros. La precitada Ley cambió la denominación del título de la normativa, “De los cubanos", como rezaba en los textos anteriores, por el "De la nacionalidad", pero regulando de manera expresa el contenido correspondiente a la ciudadanía. ${ }^{42}$ Es de notar que los derechos fundamentales, tanto los individuales como los sociales, tienen en este momento un destinatario general, que no permite señalar que sean sólo para ciudadanos.

El texto de 1940, al igual que se había hecho en 1936, cambió la denominación del título constitucional, "De los cubanos" por el "De la nacionalidad", y bajo éste se reguló de manera expresa la ciudadanía. Aquí, queriendo salvar la situación inicial, condición e institución de derecho privado para intervenir en la vida pública, embrolla - como era usual por entonces en tanto uso indistinto- ${ }^{43}$ nacionalidad con ciudadanía.

De tal suerte, a inicios de la década de los cincuenta, la situación en cuanto a los términos se mantenía. De Montagú llegó a sostener que el vocablo "ciudadano" se empleaba en diversas leyes, sin más indicaciones, en oposición al de "extranjero"; una fórmula lacónica utilizada como sinónimo de cubano, en tanto también las leyes

\footnotetext{
${ }^{41}$ Código de Derecho Internacional Privado (Código de Bustamante) Convención de Derecho Internacional Privado, La Habana, 20 de febrero de 1928, artículo 3o: “Para el ejercicio de los derechos civiles y para el goce de las garantías individuales idénticas, las leyes y reglas vigentes en cada Estado contratante se estiman divididas en las tres clases siguientes: 10. Las que se aplican a las personas en razón de su domicilio o de su nacionalidad y las siguen aunque se trasladen a otro país, denominadas personales o de orden público interno".

${ }^{42}$ El título II de la Ley Constitucional de 1936, se denomina “De la nacionalidad” y contiene la regulación de la ciudadanía, su adquisición, pérdida y deberes de los ciudadanos, con similar contenido a los anteriores textos.

43 “La realidad es que el uso ha hecho sinónimos los conceptos de nacionalidad y ciudadanía, aunque, técnicamente, una denota la cualidad de pertenecer a una nación y la otra la de pertenecer a un Estado". Álvarez Tabío, F., Comentarios a la Constitución socialista, 1a. reimp., La Habana, Pueblo y Educación, 1988, p. 127.
} 
empleaban los vocablos "personas", "individuos" o "habitantes", cuando se querían referir a todos. ${ }^{44}$

Esa sinonimia pasó a la ley fundamental de 1959, y aunque muy específicamente también a la Constitución de $1976,{ }^{45}$ en la que pervivió hasta la reforma de 1992, en que se limita a emplear el término "ciudadanía". ¿Todo resuelto? No, pues las regulaciones adoptadas bajo aquella confusión, como antes se apuntó, perviven, lo que provoca que las medidas restrictivas para los ciudadanos afecten a los nacionales que han adquirido otros vínculos; porque además, entre los propios doctrinarios del derecho y en la práctica jurídica, se emplea el vocablo "nacionalidad" para determinar la ley aplicable cuando al amparo de la Constitución vigente deberían utilizar el término "ciudadanía".

Hemos de tener presente que, conforme al ordenamiento constitucional cubano, la nacionalidad es el vínculo sociológico, y es la ciudadanía la que genera el vínculo político-jurídico; por tanto, los derechos derivan de la ciudadanía, y ella misma puede adquirirse, no ejercitarse, renunciarse ${ }^{46}$ o ser privada de ella como sanción. Pero la problemática aumenta al no existir en la normativa ordinaria las reglas y procedimientos para su renuncia; prima la noción de la pérdida como resultado de la determinación estatal.

${ }^{44}$ Sólo queremos mencionar algunos criterios que estaban presentes en Cuba, y que de una manera u otra influyeron en la elaboración de las leyes y la consiguiente conflictualidad alrededor del mismo. Kelsen, en su Teoría general del Estado, trad. de Legaz Lacambra, 1934, p. 208, el cual emplea el término de ciudadanía para referirse a los derechos y deberes que tiene el ente natural respecto al Estado y que lo diferencia del extranjero; pero en su Teoría general del derecho y del Estado, trad. de E. García Máynez, 1949, pg. 247, estableció una sinonimia entre ciudadanía y nacionalidad desde el propio subtítulo, "La ciudadanía (o nacionalidad)" definiéndola como un estatus personal cuya adquisición y pérdida se encuentran reguladas por el derecho nacional y el derecho internacional. Entre nosotros, De Montagú, G., El Poder Judicial y la Constitución y otros estudios, 1951, p. 20; además, para este autor, la expresión cualquier ciudadano es en Cuba, por ende, gramatical y legalmente, cualquier persona que disfrute de los derechos de la ciudadanía cubana.

${ }^{45}$ Constitución de Cuba de 1940, artículo 12, inciso $c$, ley fundamental de 1959, artículo 12 inciso $c$, y la Constitución de 1976, artículo 29 inciso ch. En todos se establece que: “Son cubanos por nacimiento: Los que habiendo nacido fuera del territorio de la República de padre o madre natural de Cuba que hubiesen perdido esta nacionalidad, reclamen la ciudadanía cubana en la forma y con sujeción a las condiciones que señale la ley...".

${ }^{46}$ Constitución de Cuba de 1976, ref. 2002, artículo 32: “Los cubanos no podrán ser privados de su ciudadanía, salvo por causas legalmente establecidas. Tampoco podrán ser privados del derecho a cambiar de ésta". 


\section{PÉRDIDA Y MÚLTIPLE CIUDADANÍA CUBANA. UN PROBLEMA A RESOLVER}

De conformidad con lo antes expuesto, ha de tenerse en cuenta la noción prevaleciente de la pérdida de la ciudadanía.

En la tradición constitucional cubana no se advierte expresamente la renuncia como causal, bajo la concepción de que la ciudadanía originaria (confundida aquí con nacionalidad) es irrenunciable.

Así entonces, la pérdida ha sido el resultado de obtener otra, o servir a un Estado extranjero - con empleo o armas - sin permiso del gobierno cubano, presente desde 1901. ${ }^{47}$ Bastante similar se expresó en el texto de $1940^{48}$ y se mantuvo en el original texto de 1976, en el que también se detallaron las causas para su privación; ${ }^{49}$ nótese incluso el inciso c) del artículo 32 constitucional en su carácter de sanción política a los que encontrándose fuera del territorio nacional de algún modo atentarán contra

47 Constitución de Cuba de 1901, artículo 70.: “La condición de cubano se pierde: 10. Por adquirir ciudadanía extranjera; 2o. Por admitir empleo u honores de otro gobierno sin licencia del Senado; 30. Por entrar al servicio de las armas de nación extranjera sin la misma licencia; 40. Por residir el cubano naturalizado cinco años continuos en el país de su nacimiento, a no ser por razón de empleo o comisión del gobierno de la República".

${ }^{48}$ Constitución de Cuba de 1940, artículo 15: “Pierden la ciudadanía cubana: a) Los que adquieran una ciudadanía extranjera. b) Los que sin permiso del Senado entren al servicio militar de otra nación, o al desempeño de funciones que lleven aparejada autoridad o jurisdicción propia. c) Los cubanos por naturalización que residan tres años consecutivos en el país de su nacimiento, a no ser que expresen cada tres años, ante la autoridad consular correspondiente, su voluntad de conservar la ciudadanía cubana. La Ley podrá determinar delitos y causas de indignidad que produzcan la pérdida de la ciudadanía por naturalización, mediante sentencia firme de los tribunales competentes. d) Los naturalizados que aceptasen una doble ciudadanía. La pérdida de la ciudadanía por los motivos consignados en los incisos b) y c) de este artículo no se hará efectiva sino por sentencia firme dictada en juicio contradictorio ante Tribunal de Justicia, según disponga la Ley".

49 Constitución de Cuba de 1976, artículo 32: “Pierden la ciudadanía cubana: a) los que adquieran una ciudadanía extranjera; b) los que, sin permiso del gobierno, sirven a otra nación en funciones militares o en el desempeño de cargos que Ileven aparejada autoridad o jurisdicción propia; c) los que fuera del territorio de cualquier modo conspiren o actúen contra el pueblo de Cuba y sus instituciones socialistas y revolucionarias; ch) los cubanos por naturalización que residen en el país de su nacimiento, a no ser que expresen cada tres años, antes la autoridad consular correspondiente, su voluntad de conservar la ciudadanía cubana; d) los naturalizados que aceptaren una doble ciudadanía. La ley podrá determinar delitos y causas de indignidad que produzcan la pérdida de la ciudadanía por naturalización, mediante sentencia firme de los tribunales. La formalización de la pérdida de la ciudadanía por los motivos consignados en los incisos b) y c) se hace efectiva mediante decreto del Consejo de Estado". 
las instituciones del pueblo. En los tres textos antes señalados, los naturalizados que no residan en el territorio cubano deben reiterar su interés de conservar la ciudadanía o se pierde, lo cual tiene la lógica del retorno al país de origen para ejercer allí sus derechos plenos.

También en los tres, adquirir otra ciudadanía provoca la pérdida de la ciudadanía cubana. Esta previsión muestra una voluntad política directa de que los cubanos sólo ostenten una ciudadanía. De hecho, y formalmente, se hace necesaria una resolución expresa que declare la pérdida de la ciudadanía cubana, luego de haber acreditado la tenencia de la ciudadanía extranjera.

En el presente, como resultado de migraciones, algunos cubanos han adquirido la ciudadanía extranjera, la de los países en que se han residenciado, y aunque pudiera parecer de la letra constitucional, la pérdida de la ciudadanía cubana no es automática, ni podría serlo, por el carácter de la institución. Además, al no existir, ni legal ni procedimental, la vía para la renuncia de la ciudadanía originaria, siguen siendo considerados ciudadanos cubanos, y en tal condición deberán ingresar al territorio nacional.

Esta carencia también ha provocado impactos en materia de derechos, ya que en la práctica jurídico-política cubana y derivado de algunas normativas legales, ha sido la residencia la institución aseguradora de la mayoría de los derechos, produciéndose una limitación a lo constitucionalmente mandatado, en especial si tenemos en cuenta que en la mayoría de los derechos previstos los destinatarios son todos, sin distinción.

La reforma de 1992, beneficiosa en el plano económico, en materia de ciudadanía sesgó el contenido relativo a la pérdida, lo extrajo para ser regulado por ley ordinaria, y sólo conservó de manera genérica y poco precisa su enunciación. En consecuencia, no están previstas en la Constitución vigente las causas para la determinación de su pérdida, no existe ley que fije el procedimiento para ello, ${ }^{50}$ como tampoco se autoriza la judicialización de la materia constitucional ni hay práctica de aplicación directa de la Constitución en caso de omisiones legales.

Por tanto, ¿se pierde o no? Desde la teoría del derecho, valdría admitir la vigencia en el tiempo de un precepto que no ha sido expresamente derogado, que es lo que

\footnotetext{
${ }^{50}$ Constitución de Cuba de 1976, ref. 1992, artículo 32: “Los cubanos no podrán ser privados de su ciudadanía, salvo por causas legalmente establecidas. Tampoco podrán ser privados del derecho a cambiar de ésta. No se admitirá la doble ciudadanía. En consecuencia, cuando se adquiera una ciudadanía extranjera, se perderá la cubana. La ley establece el procedimiento a seguir para la formalización de la pérdida de la ciudadanía y las autoridades facultadas para decidirlo".
} 
sucede con el original artículo 32 de 1976, que es el que contiene las causales de pérdida de la ciudadanía cubana. Siguiendo elementos de lógica jurídica-política y principios de derecho, si no fueron expresamente derogadas con la reforma de 1992, no se produjo una expulsión expresa de estos artículos del texto de $1976,{ }^{51}$ como tampoco se promulgó con posterioridad una regulación contradictoria. Por ello, pregunto: ¿deberá quedarse el Estado sin la posibilidad de determinar quiénes pueden/deben perder la ciudadanía cubana? Es algo que por cuestiones de poder, autoridad y soberanía no debe obviarse, sin descontar que tal regulación, a su vez, brindaría mayor seguridad jurídica para los cubanos. Por ello, no muy lejos debe elaborarse una Ley que acoja a la letra el nuevo sentido que la institución necesita, o lo que es lo mismo, sin rechazar la pérdida, acoger la renuncia.

También del texto de 1940 hay un elemento que preserva una incidencia en el presente: la prohibición de doble ciudadanía, así como la pérdida de la ciudadanía cubana para aquellos naturalizados que aceptaren otra. ${ }^{52}$ Lo antes expuesto reitera lo consagrado en las Constituciones previas, que establecen - como ya antes se expuso- la pérdida de la ciudadanía cubana por haber adquirido otra, según se reguló en 1901 y 1976 y se mantuvo con la reforma de $1992 .{ }^{53}$ Con las adquisiciones de ciudadanía extranjera por cubanos residentes permanentemente en el territorio nacional vuelve a aparecer en la práctica la problemática antes comentada, pues se conservan las dos ciudadanías, aunque la letra y el imaginario político y popular entiendan lo contrario algunas veces. En sede de derechos no se produce afectación alguna para los cubanos con residencia permanente, que continúan disfrutándolos sin distinción, y la tenencia de la otra ciudadanía le ha producido beneficios adicionales, en particular, en materia migratoria.

\footnotetext{
${ }^{51}$ La Comisión de la Asamblea Nacional encargada de hacer los análisis del texto en pos de su reforma sostuvo que “En el capítulo II sobre la ciudadanía, la modificación principal se propone en el artículo 32, sustituyéndose el texto actual, ...muy reglamentario, por uno más flexible que remite a la ley los detalles...". Véase las actas de la Asamblea Nacional del Poder Popular en sus sesiones para aprobar la citada reforma de la Constitución, p. 14, versión digital.

${ }^{52}$ Véase la identidad en la regulación entre la Constitución de 1940, artículo 15: “Pierden la ciudadanía cubana: ...d) los naturalizados que aceptaren una doble ciudadanía"; y el texto de 1976, artículo 32: “Pierden la ciudadanía cubana: d) los naturalizados que aceptaren una doble ciudadanía".

53 Op. cit. supra, notas de la 45 a la 49 y 52.
} 
En cuanto a esta duplicidad, sería prudente recordar una diferenciación doctrinal enunciada en 1978, entre dos y doble ciudadanía. ${ }^{54}$ En aquel entonces se utilizó para distinguir entre la solicitud y la aceptación, entre el que pedía otra ciudadanía y aquel que la recibía por determinación legal u otorgamiento estatal y se daba solución a situaciones añejas, de naturalizados que retornaban a su país de origen, y conforme a sus leyes nacionales la simple residencia continua hacía que los acogiera nuevamente, o de otras más generales que nunca prevén la pérdida de la ciudadanía de origen, apareciendo entonces dos y ante dos Estados las responsabilidades, derechos y deberes.

Fue a raíz de la entrada en vigor de la ley española De la Memoria Histórica, más conocida entre nosotros como Ley de nietos, ${ }^{55}$ que apareció esta duplicidad, pues los cubanos que no tenían el interés de perder la ciudadanía cubana adquirieron la ciudadanía española con la finalidad de acceder con más facilidad a los trámites de salida del país con carácter temporal, o sea, con garantía de retorno; innecesario -al menos para salir de Cuba- con el reciente Decreto-Ley ${ }^{56}$ modificativo de la Ley migratoria, que autoriza hasta dos años fuera de Cuba sin que haya afectación de su derecho de residencia y el resto de los derechos y deberes que de ella derivan. Para los cubanos - nacionales - residentes permanentemente en el territorio nacional,

\footnotetext{
${ }^{54}$ Azcuy Henríquez, H., "Derecho constitucional”, cap. La ciudadanía (conferencias mimeografiadas), publicadas bajo el título "Análisis de la Constitución cubana", Revista Papeles de la FIM, núm. 14, 2 a. época, 1998, p. 79.

55 “Adquisición de la nacionalidad española: 10. Las personas cuyo padre o madre hubiese sido originariamente español podrán optar a la nacionalidad española de origen si formalizan su declaración en el plazo de dos años desde la entrada en vigor de la presente Disposición adicional. Dicho plazo podrá ser prorrogado por acuerdo del Consejo de Ministros hasta el límite de un año. 20. Este derecho también se reconocerá a los nietos de quienes perdieron o tuvieron que renunciar a la nacionalidad española como consecuencia del exilio". Ley 52/2007, de la Memoria Histórica España, Boletín Oficial del Estado, núm. 310, disposición adicional séptima, en http://Www.boe.es/boe/dias/2007/12/27/pdfs/A5341053416.pdf.

56 Decreto-Ley núm. 302, modificativo de la Ley núm. 1312, “Ley de migración” de 20 de septiembre de 1976, GO. núm. 44, del 16 octubre 2012, artículo 9o., inciso 20.: "Se considera que un ciudadano cubano ha emigrado, cuando viaja al exterior por asuntos particulares y permanece de forma ininterrumpida por un término superior a los 24 meses sin la autorización correspondiente, así como cuando se domicilia en el exterior sin cumplir las regulaciones migratorias vigentes". El Reglamento de esta Ley define los supuestos para autorizar la permanencia en el exterior por un término superior al establecido en el párrafo anterior.
} 
está claro que mantienen la ciudadanía cubana, pudiendo sólo ostentar la otra condición y ejercer tales derechos fuera de Cuba.

Son los cubanos que han migrado y adquirido otra ciudadanía a los que se le presenta la ambivalencia, pues dentro del territorio nacional —como pauta general— sólo serán considerados cubanos, y con limitaciones en el ejercicio de sus derechos pues - como antes se dijo- no son residentes. Al respecto, valdría decir que en este caso tampoco hay doble ciudadanía, sino dos ciudadanías, y en cuanto a ello también merece analizar el círculo de los derechos que derivarán de tal situación, junto a los ya previstos deberes de respeto a la ley nacional.

El hecho es que la expresión "no se admitirá la doble ciudadanía" ha de suponer la imposibilidad de actuar, ejercer derechos y cumplimentar deberes a la vez respecto a los dos Estados con los que se vincula. En tal sentido, sería conveniente la incorporación del par categorial anterior al lenguaje oficial para dar solución a estas y otras situaciones que pudieran presentarse, resultado de la interconexión que se presenta entre residencia, nacionalidad y ciudadanía, algo que también merece diferenciación.

Consiguientemente, ha de entenderse como válido tanto el derecho de cambiar de ciudadanía como de adquirir otra; pero en territorio nacional no tiene lógica —en cuanto al disfrute de derechos, como tampoco relativo a la exigencia de deberes para con la sociedad y el Estado- aceptar renuncia o pérdida de la primera, sino que se podrán tener dos ciudadanías, pero sólo se podrá hacer valer una, la efectiva, de conformidad con el lugar de residencia y domicilio legal. Y esto es dos ciudanías.

No se puede tener a la par, y con un uso indistinto a voluntad del titular individual, doble vínculo activo con Estados diferentes; como tampoco puede el cubano que adquiriera otra, estando en Cuba, escoger la otra ciudadanía antes que la primera, y menos querer hacer valer aquellos derechos antes que éstos; como tampoco tiene por qué un Estado decidir lo que le corresponde a otro; eso sería atentar contra la soberanía.

Pero dosciudadanías sí se pueden, una pasiva y otra en ejercicio; así entonces, en Cuba el cubano sólo podrá ostentar, reclamar y ejercer los derechos y deberes que derivan del vínculo político-jurídico con el Estado cubano, a partir de la primacía del ius solis, del principio de que nadie es extranjero en su país de origen, y que nadie puede tener dos patrias a la vez. Una forma de preservar la identidad cultural del ser cubano. 
De conformidad con el importante papel que desempeña la ciudadanía en la determinación de la ley aplicable, como garantía formal básica de la posibilidad de disfrute de los derechos humanos en toda su amplitud, sin limitaciones, y de protección jurídica de la persona dondequiera que se encuentre, se hace necesario clarificar tanto su definición como su regulación, a fin de evitar las confusiones y contradicciones en cuestiones técnicas y prácticas, que afectan el estatus mismo del hombre en la sociedad.

De igual manera, es prudente revalorar la regla de la pérdida de la ciudadanía cubana por adquirir una extranjera y dando la posibilidad de tener dos ciudadanías, especialmente en vínculo de nuestro entorno latinoamericano. Cierto que es un precepto, que con variaciones ha venido apareciendo en nuestras Constituciones, y que se incluyó como resultado de las características de formación del Estado cubano en los finales del siglo XIX; pero hoy tenemos otras condiciones, y hay mayor movilidad de los cubanos y mayor intercambio con todo el subcontinente.

\section{CONCLUSIONES}

Si las nociones doctrinales, condicionadas por las situaciones que son su caldo de cultivo u origen, tienen expresión normativa, la misma dialéctica social obliga a su revaloración ante las nuevas circunstancias. Hacerlas pervivir, desconociendo la intervinculación dialéctica derecho y sociedad, es aferrarse a interpretaciones históricas o literales y obviar la incidencia social que la institución tiene, en este caso sobre la persona y sus derechos.

Desde esa evidente pervivencia de principios que definen tanto lo cubano como la ciudadanía cubana, pueden y deben efectuarse reformulaciones que contribuyan a crear reglas generales más adecuadas a estos tiempos. Así entonces, es prudente que se diferencie expresa y formalmente nacionalidad y ciudadanía, que se clarifiquen los derechos que condiciona la residencia, que sea la ciudadanía la institución básica que asegure derechos y deberes, y que en cuanto a las dos y doble, o se modifica la letra constitucional, o se realiza una interpretación que establezca las diferencias terminológicas entre doble y dos ciudadanías.

\section{BIBLIOGRAFÍA}

Álvarez Tabío, F. Comentarios a la Constitución socialista, La Habana, Pueblo y Educación, 1988.

ANDRENACCI, L., “Imparis civitatis. Elementos para una teoría de la ciudadanía desde una perspectiva histórica", Memoria Académica, FaHCE, Cuadernos del CISH, núm. 
Esta revista forma parte del acervo de la Biblioteca Jurídica Virtual del Instituto de Investigaciones Jurídicas de la UNAM

http://www.memoria.fahce.un/p.edu.ar/art_revistas/pr.379/pr.379.pdf.

ARISTÓTELES,

Política,

http://bib.cervantesvirtual.com/servlet/SirveObras/13561630989134941976613/in dex.htm.

AzCuy HenríqueZ, H., "Análisis de la Constitución cubana", Revista Papeles de la FIM, 2a. época, núm. 14, 1998.

BoRjA, J., "La ciudad y la nueva ciudadanía", conferencia Fórum Europa, Barcelona, junio 2001, http://www.diba.cat/forumeuropa/documents.2001/Borja.doc.

De Montagú, G., El poder judicial y la Constitución y otros estudios, 1951.

FATÁs, G., Historia de Zaragoza, I, Zaragoza, 1997, http://webu2.upmfgrenoble.fr/DroitRomain/Spanica/pompei_esp.htm/.

Gaudemet, J., Les institutions de l'antiquité, 7a. ed., Paris, 2002, http://webu2.upmfgrenoble.fr/DroitRomain/Francogallica/Caracalla_fran.htm.

KeLSEN, H., Teoría general del Estado, trad. de Legaz Lacambra, Barcelona, Labor, 1934.

- - , H. Teoría general del derecho y del Estado, trad. E. García Máynez, México, Imprenta Universitaria, 1949.

KYMLICKA, W. y NORMAN, W., “El retorno del ciudadano. Una revisión de la producción reciente en teoría de la ciudadanía", AsorA, núm. 7, 1997, http://courseware.url.edu.gt.

LINDE, E., "La ciudadanía europea: un peldaño en la construcción del hombre de nuestro tiempo", http://dialnet.unirioja.es

MARSHALL, Th., "Ciudadanía y clases sociales", Revista Española de Investigaciones Sociológicas, núm 79, julio-septiembre, 1997.

RousSEAU, J. J., "El contrato social”, Obras escogidas, La Habana, Ciencias Políticas, Edit. Ciencias Sociales, 1973.

Real Academia Española, Diccionario de la Real Academia Española, 22a . ed., 2010. 